\title{
Relationship Between the Innovative Organizational Culture and Teachers' Competence for Building an Early Childhood Educational Community: The Mediating Effects of Teachers' Relational Satisfaction with the Principal and Colleagues
}

\author{
Kai-sook Chung ${ }^{1}$, Hee-kyung Park ${ }^{2}$, Jiyeon Kim ${ }^{3}$ \\ Professor, Department of Early Childhood Education, Pusan National University, Busan, Korea ${ }^{1}$ \\ Research Professor, Ddadeutan (Warm) Educational Community Research Center (SSK), Pusan National \\ University, Busan, Korea \\ Ph. D. Candidate, Department of Early Childhood Education, Pusan National University, Busan, Korea ${ }^{3}$ \\ 유아교육기관의 혁신문화와 교사의 유아교육공동체 구현 역량과의 관계: \\ 원장과 동료교사와의 관계만족도의 매개효과 \\ 정계숙 ${ }^{1}$, 박희경 ${ }^{2}$, 김지연 ${ }^{3}$ \\ 부산대학교 유아교육과 교수 ${ }^{1}$, 부산대학교 따뜻한교육공동체연구센터(SSK) 연구교수 ${ }^{2}$, 부산대학교 유아교육과 박사수료 ${ }^{3}$
}

Objectives: To examine the mediating effects of early childhood teachers' relational satisfaction with the principal and colleagues on the relationship between the innovative organizational culture of early childhood education institutes and teachers' competence for building an early childhood educational community.

Methods: The participants were 590 teachers, and they answered questions from three rating scales. Descriptive analysis, correlations analysis, and regression analysis were conducted on the collected data. Additionally, mediation analysis was conducted using bootstrapping techniques for testing multiple mediators by Hayes's Process macro for SPSS.

Results: First, there were significant correlations between the innovative organizational culture of early childhood education institutes and the teacher's relationship satisfaction with principal and colleagues and competence for building an early childhood educational community. Second, the teacher's relationship satisfaction with colleagues had a partial mediating effect on the relationship between the innovative organizational culture of the institutes and the teacher's competence for building an early childhood educational community.

Conclusions: The results of this study provide suggestions for supporting a formation of an innovative organizational culture and enhancing teachers' relationship satisfaction with colleagues for building an early childhood educational community.

Keywords: innovative organizational culture, early childhood educational community, teacher's competence, relational satisfaction

Corresponding Author: Hee-kyung Park, Research Professor, Ddadeutan (Warm) Educational Community Research Center (SSK), Pusan National University, 2, Busandaehak-ro 63beon-gil, Geumjeong-gu, Busan, 46241, Korea

E-mail: yimhk9@pusan.ac.kr
(C) The Korean Association of Child Studies

This is an Open Access article distributed under the terms of the Creative Commons Attribution Non-Commercial License (http:// creativecommons.org/licenses/by-nc/4.0) which permits unrestricted noncommercial use, distribution, and reproduction in any medium, provided the original work is properly cited. 


\section{Introduction}

최근 아동학대를 의심받은 보육교사가 스스로 목숨을 끊는 안 타까운 일이 발생하였다(K. M. Park, 2018). 이는 현재 교사와 부모 간의 불신이 유아교육기관에 존재함을 단적으로 보여주 는 사건으로, 교실 내 CCTV의 설치가 유아교사와 부모의 관 계를 단절시키고 유아교사에게 사기 저하와 좌절감 혹은 자괴 감을 경험하게 함으로써 전통적으로 구성원들 간의 관계와 소 통을 통한 신뢰와 협력을 어느 학교급보다 강조해온 유아교육 의 기반이 크게 흔들리고 있음을 확인해주었다. 게다가 사립 유치원 회계 비리 사태가 전국적으로 발생하면서 유아교육기 관에 대한 부모와 사회의 불신이 더욱 확산되고 있다. 이는 교 육의 주체인 유아, 교사 및 부모가 함께 만들어가는 교육공동 체로서 유아교육기관의 건강성은 위험 수준에 이르렀음을 보 여주며 이를 해결하기 위한 적극적인 노력이 필요함을 시사한 다.

학교는 유기체적 생명체들로 구성되어 있는 유기체이므로 (S. H. Han, 2000) 건강한 유아교육은 구성원 간의 진정한 상 호 돌봄과 배움의 관계를 통해 서로의 생명성을 북돋우는 교 육공동체(K. Chung, Yoon, Kyun, Cha, \& Park, 2016)를 통해 구 현될 수 있다. 즉, 유아교육기관 또한 다른 학교 급과 마찬가 지로 심리적 안전감, 소속감, 개인 상호간 및 집단 간에 관련 을 맺고 있다는 느낌, 헌신을 통해 구성원의 욕구를 충족시킬 수 있다는 공유된 신념 등이 있는 강력한 정서적 결합체인 교 육공동체(K. Chung et al., 2018)를 이루는 것이 유아교육의 건 강성을 지키기 위해 구성원들이 함께 노력해나가야 할 방향일 것이다. 이에 유아교육기관이 교육공동체로서의 건강성을 유 지해나가기 위해 유아교육 종사자들이 우선적으로 해야 할 일 은 사기가 저하되고 위축된 유아교사가 유아교육공동체 구현 을 위해 그들의 역량을 발휘할 수 있도록 힘을 실어주는 것이 라고 본다. Malaty (2006)는 실증적으로 성공적인 교육 변화를 이끄는 요인으로 획기적인 개혁보다는 점진적인 개혁의 꾸준 한 추진, 평등과 협동의 교육철학 등과 함께 무엇보다도 역량 있는 교사들이 중요하다고 제시하였다. 따라서 사회적, 교육 적으로 유아교육 분야의 내부적 변화가 요구되는 시점에 교사 의 유아교육공동체 구현 역량의 계발은 관심을 가져야 할 주 제이다.

교육공동체 구현을 위한 교사의 역량에 관한 연구는 중등 교사를 주 대상으로 한 학교공동체 구성원의 역할에 대한 Hur (2005)의 연구가 거의 전부일 만큼 연구가 부족하다. 유사하게 유아교육공동체 구현을 위한 교사의 역량도 최근에 연구되기
시작한 개념으로 관련 자료가 매우 제한되어 있다. K. Chung, Yoon과 Park (2016)은 이를 유아교육공동체로의 비전과 목표 의 변화에 대응하여 적절한 사회적, 행동적 요소와 인지적, 실 천적 기술을 교사에게 기대되는 역할상의 과제나 스스로의 요 구 충족에 성공적으로 동원하는 지식, 태도 그리고 실천능력 으로 정의하였다. 이를 토대로 유아교사가 갖춰야할 유아교육 공동체 구현을 위한 역량 척도를 개발한 결과, 교사의 유아교 육공동체 구현 역량 요인은 유아교육기관 구성원과 동반자로 역할하기 위한 심리적 역량과 가치공유를 위한 사회적 역량 이 추출된 바 있다(K. Chung, Yoon, \& Park, 2017). 구체적인 역 량 요소를 살펴보면, 동반자로서의 역할을 위한 심리적 역량 은 유아교사가 다른 구성원과 동반자 의식을 갖기 위해 갖춰 야할 역량으로 상호 신뢰감 갖기, 기관 활동에 자발적이며 적 극적으로 참여하기, 구성원에 대한 배려, 다름에 대한 수용, 긍 정적 관계를 위한 기회 조성, 구성원 전체에 전문적 돌봄 수행 하기, 유아 교육에 함께하기, 셀프 리더십 그리고 민주적 의사 소통 등이 포함되어 있다. 그리고 가치공유를 위한 사회적 역 량은 본인과 기관의 가치관과 정체성을 확립하고 지역사회 네 트워크를 통해 이를 공유할 수 있는 역량으로 교육에 대한 가 치관 공유, 자신과 기관의 정체성 확립, 사회 성장을 위한 돌 봄, 네트워크 형성하기, 그리고 건강한 풍토 형성하기 등의 요 소를 포함한다.

이러한 교사의 교육공동체 구현 역량이 어느 정도 계발될 수 있을지는 조직구성원의 태도와 행동에 영향을 미치는 조 직문화(Parker \& Bradley, 2000)의 영향을 받을 수 있다. 조직문 화는 조직의 다양한 환경에 대해서 어떻게 지각하고 생각하 고 행동할지를 결정하는 공유된 가정(Schein, 1996)으로 구성 원들의 태도와 행동, 인식에 영향을 미친다. 이에 학교조직문 화는 학교 조직의 목적을 달성하기 위해 학교 조직의 외부환 경과 학교 조직 내에서 구성원들이 문제해결 과정에서 습득하 고 공유하게 된 학교조직과 구성원 상호 간에 영향을 주는 역 동적인 문화로(Oh \& Kang, 2006), 구성원들이 받아들이고 있 는 공유된 가치, 신념, 의식과 의례, 지식과 기술 등이 포함된 다(C.-G. Kim, 2000). 그러므로 학교조직문화는 구성원들에게 영향을 주는 기본 요소라 할 수 있고, 유아교사가 유아교육공 동체 구현을 위해 자신의 역량을 계발에 있어서도 소속된 유 아교육기관의 조직문화가 주요한 영향을 미칠 것이다.

조직문화는 혁신문화, 합리문화, 집단문화, 위계문화로 유 형화할 수 있다(Kimberly \& Quinn, 1984). 이 중 혁신문화는 창의적 사고와 도전을 강조하고 새로운 활동을 과감하게 시 도하여 성장과 발전을 하는 문화로(G. W. Park \& Kwon, 2015), 
혁신문화에서 구성원들은 위험을 감수하며 도전하고 자신의 성장과 조직의 발전을 위해 자발적이고 적극적인 노력을 한다 (I.-K. Han, 2012). 그리고 혁신문화는 외부지향적인 유연한 문 화(Cameron \& Quinn, 2011)로 조직의 신축성과 재량을 강조 하면서 조직의 외부환경에 대한 적응에 초점을 두고 창의성, 모험성, 도전성 등의 가치를 중요시한다(J. Y. Lee, 2012). 특히, 혁신문화에서는 구성원들 간의 창의적 사고기술과 전문성이 공유되고 자발적이고 지속적으로 연결되어, 환경변화에 신속 히 대응하고 조직의 공동목표 달성을 위한 공유 행위가 나타 난다(G. S. Lee \& Hwang, 2017). 따라서 혁신문화는 유아교사 의 교육공동체 구현 역량을 증진시켜 조직의 건강성을 위협받 고 있는 각 유아교육기관이 교육공동체로 나아갈 수 있도록 돕는 더욱 강화되어야 할 조직문화이다. 유아교사들이 구성원 과 동반자로서 함께 하는 심리적 역량과 그들과 유아교육의 가치를 공유하는 사회적 역량을 계발하는데 있어 혁신문화는 그 실천적, 경험적 기반이 될 것으로 사료되기 때문이다. 이에 실증적으로 혁신문화가 교사의 유아교육공동체 구현 역량에 미치는 영향을 확인할 필요가 있다.

또한 혁신문화는 유아교사의 원장과 동료교사와의 관계만 족도에도 영향을 미칠 것으로 판단된다. 조직문화를 통해 조 직구성원 간의 관계를 맺는 방식에 대한 신념과 기대가 형성 되는데(Fullan \& Hargreaves, 1996), 혁신문화는 자유로운 분위 기에서 조직의 변화와 혁신을 위한 제언이나 아이디어가 받아 들여질 수 있도록 하고(G. W. Park \& Kwon, 2015) 개방적 상호 작용, 모험과 도전, 신속하고 융통성 있는 업무치리와 같은 특 성이 비교적 강하다(Ohem \& Jeong, 2011). 이에 유아교육기관 에서 혁신문화는 창의적인 프로그램 개발, 문제해결 방식에서 의 융통성, 새로운 교수방법의 적용, 교사간의 자유로운 의견 교환의 허용 등이 마련된다(Kang, 2015). 이러한 혁신문화의 특징을 가진 유아교육기관일수록 유아교사들이 자유롭고 개 방적인 분위기에서 서로의 생각을 공유하고 수용하며 자신의 성장과 조직의 발전을 위해 자발적이고 적극적으로 노력하는 과정에서 동료교사는 물론 이를 지원하는 원장과도 긍정적인 관계를 맺게 되고 관계에 대한 만족도가 높아지게 될 것이다. K. Chung, Yoon과 Moon (2017)의 연구에서 혁신문화는 동료 교사와 원장, 유아와 부모를 포함한 기관 구성원 전반과의 관 계만족도에 영향을 주는 것으로 밝혀졌다. 이렇듯 유아교사의 원장과 동료교사와의 관계만족도는 교사 개인의 심리적 건강 성과 유아교육기관의 지속가능한 발전에 중요한 의미를 갖는 다는 점에서 이를 증진시킬 것으로 예측되는 혁신문화의 영향 을 밝히는 작업은 시의적절하다고 하겠다.
한편, 유아교사의 원장과 동료교사와의 관계만족도는 유 아교육기관의 지속가능한 발전에 직접적인 동력을 제공하는 교사 역량 요인 중 하나인 유아교육공동체 구현 역량을 강화 시켜주는 자원이 될 수 있다. Fredrickson (2009/2015)의 확장구축이론에 따르면 개인의 긍정적 경험은 심리적 강점, 사회 적 자원 등 삶의 자원을 갖도록 해주는데, 사람을 지향하는 일 인 교육(Hawes, 1989)을 수행하는 교사에게 동료교사와 원장 과의 관계에서의 만족스런 경험은 교육공동체 구현에 필요한 역량을 지원하는 요인이 될 것이다. 구성원과의 관계만족감이 높은 교사는 자신의 직무에 애착을 가지고 헌신하게 되며 학 교조직에 소속감을 가지고(Y. K. Lee, 1998; Mathieu \& Zajac, 1990; E. H. Seo \& Lee, 2002), 유아교육기관의 구성원 간 의사 소통의 질이 높은 것으로 나타났는데(E. Y. Kim, 2011; Koh \& Lee, 2017; A.-K. Lee, Yeo, Jung, \& Byun, 2013; Y.-J. Lee \& Kang, 2014), 이러한 요인은 유아교육공동체 구현과 밀접히 관련되 어 있다. 이에 유아교사의 원장과 동료교사와의 관계만족도는 교사의 유아교육공동체 구현 역량에 긍정적 영향을 줄 수 있 을 것으로 사료된다. 또한, 혁신문화가 교사의 원장과 동료교 사와의 관계만족도에 미치는 영향을 고려하면 원장과 동료교 사와의 관계만족도는 혁신문화가 교사의 유아교육공동체 구 현 역량에 미치는 영향에 매개역할을 할 것으로 예측 가능하 다.

이에 본 연구는 유아교육기관의 혁신문화는 교사의 원장과 동료교사와의 관계만족도를 매개로 하여 교사의 유아교육공 동체 구현 역량에 영향을 미치는지 세 변인들 간의 관계를 밝 히고자 한다. 이를 통해 교사의 유아교육공동체 구현 역량에 직, 간접의 영향을 미치는 요인을 밝힘으로써 시기적으로 현 장 실천의 필요성이 높아진 유아교육공동체 구현을 위해 교사 역량을 효과적으로 증진시킬 수 있는 교사 지원 방향과 유아 교육기관의 조직문화 형성에 대한 시사점을 얻고자 한다.

\section{연구문제 1}

유아교육기관의 혁신문화, 교사의 원장과 동료교사와의 관계 만족도 및 교사의 유아교육공동체 구현 역량 간의 관계는 어 떠한가?

\section{연구문제 2}

유아교육기관의 혁신문화와 교사의 유아교육공동체 구현 역 량과의 관계에서 교사의 원장과 동료교사와의 관계만족도는 매개효과가 있는가? 


\section{Methods}

\section{연구대상}

본 연구의 대상은 $\mathrm{A}$ 도와 $\mathrm{B}$ 시의 유치원 교사 218 명과 어린이 집 교사 354 명으로 총 590 명이었다. 이들에 대한 자세한 일반 적 배경은 Table 1 과 같다.

Table 1

Demographic Information of Participants

\begin{tabular}{|c|c|c|c|}
\hline & & $n$ & $\%$ \\
\hline \multirow[t]{3}{*}{ Age (years) } & $20 s$ & 311 & 52.7 \\
\hline & $30 s$ & 163 & 27.6 \\
\hline & 40 s or more & 116 & 19.7 \\
\hline \multirow[t]{3}{*}{ Institution type } & Kindergarten & 218 & 36.9 \\
\hline & Child care center & 354 & 60.0 \\
\hline & No response & 18 & 3.1 \\
\hline \multirow[t]{5}{*}{ Career duration (years) } & Less than 2 years & 139 & 23.6 \\
\hline & 3 years -4 years & 145 & 24.6 \\
\hline & 5 years -9 years & 197 & 33.4 \\
\hline & 10 years or more & 107 & 18.1 \\
\hline & No response & 2 & 0.3 \\
\hline \multirow[t]{6}{*}{ Age of children in the class } & 1 & 105 & 17.8 \\
\hline & 2 & 117 & 19.8 \\
\hline & 3 & 120 & 20.4 \\
\hline & 4 & 109 & 18.5 \\
\hline & 5 & 110 & 18.6 \\
\hline & No response & 29 & 4.9 \\
\hline \multirow[t]{4}{*}{ Education } & College & 246 & 41.7 \\
\hline & University & 312 & 52.9 \\
\hline & Graduate school & 30 & 5.0 \\
\hline & No response & 2 & 0.4 \\
\hline Total & & 590 & 100 \\
\hline
\end{tabular}

\section{연구도구}

\section{원장·동료교사와의 관계만족도}

유아교사의 원장과 동료교사와의 관계만족도는 유아교사들 이 인식하는 원장과 동료교사와의 관계에서 경험하는 만족의 정도이다. 이를 측정하기 위하여 S.-Y. Cho (2004)의 유치원 교 사 직무만족도 척도를 수정한 D.-H. Shin (2004)의 보육교사 직무만족도 척도 중 일부 요인을 선택적으로 사용하였다. 본
도구는 원장과의 관계만족도 8 문항 그리고 동료교사와의 관 계만족도 3문항 등 총 11문항으로 구성된 5점 Likert 척도였다. 따라서 총점의 범위는 11점 55점으로 점수가 높을수록 관계 만족도가 높은 것을 의미한다. 본 연구에서 문항 신뢰도는 문 항제거 신뢰도를 우선 확인하여 문항 제거 여부 확인하여 제 거할 문항은 없는 것으로 나타났다. 이에 최종 문항 신뢰도 Cronbach's $\alpha$ 는 원장과의 관계만족도 .95, 동료교사와의 관계 만족도 .84였다.

\section{혁신문화}

유아교사가 근무하는 기관의 혁신문화를 측정하기 위하여 $\mathrm{Y}$. R. Seo (2006)가 초등학교의 조직문화를 측정하기 위해 활용 한 조직문화척도를 M. Park (2012)이 유아교육기관에 적합하 게 수정한 조직문화척도를 활용하여 혁신문화 수준을 측정하 는 문항을 추출하여 사용하였다. 혁신문화를 측정하는 문항은 “조직 내 창의성, 혁신성 등의 변화 가치들을 중시한다.", "교 사들은 유아들의 욕구에 맞게 다양한 교수-학습방법을 적용 한다.” 등 총 5 문항으로 5점 Likert 척도로 평정하도록 되어 있 어, 총점의 범위는 5점 25점 사이이며 점수가 높을수록 기관 의 혁신문화적 특징이 높음을 의미한다. 본 연구에서 문항 신 뢰도는 문항제거 신뢰도를 우선 확인하여 문항 제거 여부 확 인하여 제거할 문항은 없는 것으로 나타났다. 이에 본 연구의 문항 내적 일치도 Cronbach's $\alpha$ 는 .83이었다.

\section{교사의 유아교육공동체 구현 역량}

교사의 유아교육공동체 구현 역량을 측정하기 위해 K. Chung 등(2017)이 개발한 유아교육공동체 구현을 위한 교사역량 척 도를 사용하였다. 이 척도는 유아교육공동체를 진정한 상호 돌봄과 배움의 관계를 통해 구성원 서로의 생명성을 북돋우어 생명의 온기인 따뜻함을 나누는 공동체로 정의하고 이를 구현 하기 위해 교사가 갖춰야할 역량을 측정하고자 개발되었다. 이는 동반자 역할수행을 위한 심리적 역량요인과 가치공유를 위한 사회적 역량요인으로 구성되어 있다. 동반자 역할수행을 위한 심리적 역량은 9개의 하위요인(상호 신뢰감 갖기, 기관 활동에 자발적이며 적극적으로 참여하기, 구성원에 대한 배 려, 다름에 대한 수용, 긍정적 관계를 위한 기회 조성, 구성원 전체에 전문적 돌봄 수행하기, 유아 교육 함께하기, 셀프 리더 십 그리고 민주적 의사소통)을 포함하고, 가치공유를 위한 사 회적 역량은 5 개의 하위요인(교육에 대한 가치관 공유, 자신 
과 기관의 정체성 확립, 사회성장을 위한 돌봄, 네트워크 형성 하기, 그리고 건강한 풍토 형성하기)을 포함한다. 각 하위요인 은 지식, 태도, 실천의 3 문항으로 구성되어 두 요인은 각각 27 문항과 15문항으로 전체 척도는 총 42문항이었으며 6점 Likert 척도로 평정되었다. 이에 총점의 범위는 42점 252점으로 점 수가 높을수록 유아교육공동체 구현에 필요한 역량이 높음을 의미한다. 본 연구에서 문항 신뢰도는 문항제거 신뢰도를 우 선 확인하여 문항 제거 여부 확인하여 제거할 문항은 없는 것 으로 나타났다. 이에 문항 내적 일치도 Cronbach's $\alpha$ 는 동반자 역할 수행을 위한 심리적 역량 .96 그리고 가치공유를 위한 사 회적 역량은 .93 이었다.

\section{연구절차}

본 연구는 $\mathrm{A}$ 도와 $\mathrm{B}$ 시에 위치한 유치원과 어린이집 원장 또는 주임교사를 통해 연구 참여에 동의한 교사 600 명을 표집한 후 설문지를 이메일 또는 직접 배부하고 회수하였다. 배부된 설 문지 중 회수되지 않은 설문지와 불성실한 답변을 한 설문지 를 제외한 590 부에 대하여 최종 자료 분석을 실시하였다.

\section{자료분석}

수집된 자료는 통계프로그램 SPSS 23 (IBM Co., Armonk, NY) 을 이용하여 분석을 실시하였다. 변인들 간의 관계는 Pearson 의 적률상관분석과 Baron과 Kenny (1986)가 제안한 인과단계 전략 절차에 따른 중다회귀분석을 통해 살펴보았다. Baron과 Kenny (1986)가 제안한 인과단계전략 절차는 매개효과를 확 인하는 방법으로 3 단계 회귀분석 단계를 거친다. 1 단계는 독
립변수와 종속변수 간의 유의미한 영향력을 확인한다. 2 단계 는 독립변수와 매개변수 간의 유의미한 영향력을 확인한다. 3 단계는 독립변수와 매개변수를 함께 투입하여 독립변수의 베 타 값이 유의미하지 않거나 1 단계의 베타 값보다 작아지는지 를 확인하여 매개변수의 유의미한 매개효과 유무를 판단한다. 이를 바탕으로 유아교육기관의 혁신문화와 교사의 유아교육 공동체 구현 역량과의 관계에서 교사의 원장과 동료교사와의 관계만족도의 매개효과 검증은 Hayes (2019)의 Process macro for SPSS를 활용하여 부트스트래핑을 실시하였다.

\section{Results}

\section{유아교육기관의 혁신문화와 교사의 원장과 동료교사와의 관계만족도 및 유아교육공동체 구현 역량 간의 상관관계}

유아교육기관의 혁신문화와 교사의 원장과 동료교사와의 관 계만족도 그리고 유아교육공동체 구현 역량 간의 관계를 상관 분석을 통해 살펴본 결과, Table 2 와 같다. 이를 살펴보면, 혁신 문화와 교사의 원장과 동료교사와의 관계만족도 및 유아교육 공동체 구현 역량 간에는 $r$ 값이 .35 .66의 상관이, 교사의 원 장과 동료교사와의 관계만족도는 유아교육공동체 구현 역량 요인들과 .27 . 45 사이의 유의미한 정적 상관을 보였다 $(p<$ .001). 이에 유아교육기관의 혁신문화와 교사의 원장과 동료 교사의 관계만족도 그리고 유아교육공동체 구현 역량 간에는 정적 상관이 있으며, .80 이하의 상관을 보여 변인 간의 다중공 선성은 없다는 것을 알 수 있다.

Table 2

Correlations with Innovative Organizational Culture, Relational Satisfaction with Principal and Colleagues and Teachers' Competence for Building Early Childhood Educational Community

\begin{tabular}{|c|c|c|c|c|c|c|}
\hline & & \multirow{2}{*}{ Innovative organizational culture } & \multicolumn{2}{|c|}{ Relational satisfaction } & \multicolumn{2}{|c|}{ Teachers' competence } \\
\hline & & & Principal & Colleagues & Partnership & Sharing value \\
\hline \multicolumn{2}{|c|}{ Innovative organizational culture } & - & & & & \\
\hline Relational satisfaction & Colleagues & $.55^{* * *}$ & $.50^{* * *}$ & - & & \\
\hline Teachers' competence & Partnership & $.35^{* * *}$ & $.31^{* * *}$ & $.45^{* * *}$ & - & \\
\hline$S D$ & & 0.57 & 0.77 & 0.59 & 0.51 & 0.57 \\
\hline
\end{tabular}

${ }^{* * *} p<.001$. 
Table 3

Mediating Effects: Psychological Competence for Practice of Partnership

\begin{tabular}{|c|c|c|c|c|c|c|c|}
\hline & & $B$ & $S E$ & $\beta$ & $t$ & $R^{2}$ & $F$ \\
\hline 1 & $\begin{array}{l}\text { Innovative organizational culture } \\
\rightarrow \text { Psychological competence for practice of partnership }\end{array}$ & 0.32 & 0.03 & 0.35 & $9.50^{* * *}$ & 0.13 & $90.21^{* * *}$ \\
\hline 2 & $\begin{array}{l}\text { Innovative organizational culture } \\
\rightarrow \text { Relational satisfaction with colleagues }\end{array}$ & 0.56 & 0.03 & 0.55 & $16.42^{* * *}$ & 0.30 & $269.59^{* * *}$ \\
\hline \multirow{2}{*}{3} & $\begin{array}{l}\text { Relational satisfaction with principal } \\
\rightarrow \text { Psychological competence for practice of partnership }\end{array}$ & 0.03 & 0.03 & 0.04 & 0.78 & & \\
\hline & $\begin{array}{l}\text { Relational satisfaction with colleagues } \\
\rightarrow \text { Psychological competence for practice of partnership }\end{array}$ & 0.31 & 0.04 & 0.36 & $8.22^{* * *}$ & & \\
\hline
\end{tabular}

${ }^{* * *} p<.001$.

\section{혁신문화와 교사의 유아교육공동체 구현 역 량의 관계에서 원장과 동료교사와의 관계만 족도의 매개효과}

혁신문화와 동반자역할 수행을 위한 심리적 역 량과의 관계

독립변인인 혁신문화가 매개변인인 원장과의 관계만족도와 동료교사와의 관계만족도가 동반자역할 수행을 위한 심리적 역량에 미치는 영향을 알아보기 위해 Baron과 Kenny (1986)의 인과단계전략 절차에 따라 회귀분석을 실시하였다. 그 결과 (Table 3), 1단계로 독립변인인 혁신문화가 종속변인인 동반자 역할 수행을 위한 심리적 역량에 미치는 영향을 살펴본 결과, $F$ 값이 $90.21(p<.001)$ 로 유의미한 것으로 나타났고 $B$ 값은 $0.32(p<.001)$ 고 설명력은 $13 \%$ 였다. 2 단계로 혁신문화가 원 장과의 관계만족도에 미치는 영향은 $F$ 값이 479.75 ( $p<.001)$ 로 유의미하였으며 $B$ 값은 0.88 ( $p<.001)$ 이고 설명력은 $43 \%$ 로 나타났고, 동료교사와의 관계만족도에서는 $F$ 값이 269.59 ( $p<.001)$ 로 역시 유의미하였고 $B$ 값은 0.56 ( $p<$ < 001)이고 설 명력은 $30 \%$ 로 나타났다. 3 단계로 독립변인인 혁신문화와 매 개변인인 원장과의 관계만족도와 동료와의 관계만족도가 종 속변인인 동반자역할 수행을 위한 심리적 역량에 미치는 영 향을 살펴보면, $F$ 값은 58.85 ( $p<.001$ )로 나타났으며, 설명력 은 $22 \%$ 였다. 또한 혁신문화와 동반자역할 수행을 위한 심리 적 역량과의 관계에서 $B$ 값은 $0.12(p<.001)$ 로 나타났다. 즉, 매개변인인 원장과의 관계만족도와 동료교사와의 관계만족
도가 투입됨에 따라 설명력은 증가하였고, 혁신문화와 동반자 역할 수행을 위한 심리적 역량의 $B$ 값은 앞서 0.32 에서 0.12 로 줄어들었다. 이는 혁신문화와 동반자역할 수행을 위한 심리적 역량과의 관계에서 원장과의 관계만족도와 동료교사와의 관 계만족도가 부분적으로 매개효과를 가짐을 의미한다. 한편, 원장과의 관계만족도는 동반자역할을 위한 심리적 역량에 유 의미한 영향을 미치지 않고 $(B=0.03)$ 동료교사와의 관계만족 도는 유의미한 영향을 미치는 것으로 나타났다 $(B=0.31, p<$ .001).

이에 매개효과를 검증하기 위하여 Process macro for SPSS (Hayes, 2019)를 활용하여 부트스트랩핑으로 표본 수 5,000개 를 재추출하고, $95 \%$ 신뢰구간에서 간접효과 계수의 하한값 (LLCI)과 상한값(ULCI)을 확인하였다(Table 4). 그 결과, 전체 간접효과 크기는 0.19 였으며, 하한값은 0.13 , 상한값은 0.26 으 로 $95 \%$ 신뢰구간 내에 0이 포함되지 않아 간접효과가 유의미 한 것으로 나타났다. 구체적으로 원장과의 관계만족도의 효과 크기는 0.02 고 하한값이 -0.04 , 상한값이 0.08 로 $95 \%$ 신뢰구 간 내에 0 을 포함하고 있어 간접효과가 유의미하지 않은 반면, 동료교사와의 관계만족도의 효과크기는 0.17 이고 하한값이 0.12 , 상한값이 0.22 로 $95 \%$ 신뢰구간 내에 0 이 포함되지 않아 간접효과가 유의미한 것으로 나타났다. 즉, 혁신문화와 동반 자역할을 위한 심리적 역량과의 관계에서 매개변인인 원장과 의 관계만족도와 동료교사와의 관계만족도 중에서 동료교사 와의 관계만족도만 통계적으로 유의미한 매개효과가 있는 것 으로 볼 수 있다. 이에 최종 매개효과 모형은 Figure 1과 같다. 
Table 4

The Indirect Effects: Psychological Competence for Practice of Partnership

\begin{tabular}{lcccc}
\hline & & & \multicolumn{2}{c}{$95 \%$ CI } \\
\cline { 3 - 5 } \multicolumn{1}{c}{ Mediators } & Effect & $S E$ & LLCI & ULCI \\
\hline Total & 0.19 & 0.03 & 0.13 & 0.26 \\
Relational satisfaction with principal & 0.02 & 0.03 & -0.04 & 0.08 \\
Relational satisfaction with colleagues & 0.17 & 0.02 & 0.12 & 0.22 \\
\hline
\end{tabular}

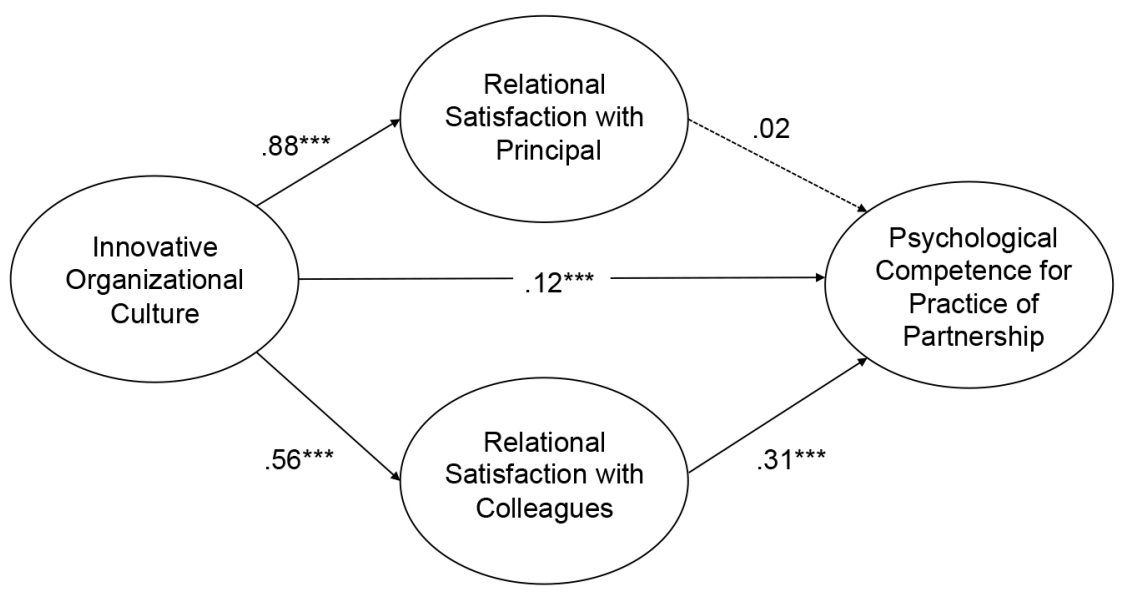

Figure 1. Mediation model: Psychological competence for practice of partnership.

${ }^{* * *} p<.001$.

Table 5

Mediating Effect: Social Competence for Sharing the Value

\begin{tabular}{|c|c|c|c|c|c|c|c|}
\hline & & $B$ & $S E$ & $\beta$ & $t$ & $R^{2}$ & $F$ \\
\hline 1 & Innovative organizational culture & 0.35 & 0.04 & 0.35 & $9.43^{* * *}$ & 0.12 & $89.01^{* * *}$ \\
\hline \multirow{3}{*}{2} & $\rightarrow$ Social competence for sharing the value & & & & & & \\
\hline & Innovative organizational culture & 0.88 & 0.04 & 0.66 & $21.90^{* * *}$ & 0.43 & $479.75^{* * *}$ \\
\hline & $\begin{array}{l}\rightarrow \text { Relational satisfaction with principal } \\
\text { Innovative organizational culture } \\
\rightarrow \text { Relational satisfaction with colleagues }\end{array}$ & 0.56 & 0.03 & 0.55 & $16.42^{* * *}$ & 0.30 & $269.59^{* * *}$ \\
\hline \multirow[t]{3}{*}{3} & $\begin{array}{l}\text { Innovative organizational culture } \\
\rightarrow \text { Social competence for sharing the value }\end{array}$ & 0.22 & 0.05 & 0.23 & $4.38^{* * *}$ & 0.16 & $40.93^{* * *}$ \\
\hline & Relational satisfaction with principal & 0.00 & 0.04 & 0.00 & -0.04 & & \\
\hline & $\begin{array}{l}\rightarrow \text { Social competence for sharing the value } \\
\text { Relational satisfaction with colleagues } \\
\rightarrow \text { Social competence for sharing the value }\end{array}$ & 0.23 & 0.04 & 0.24 & $5.27^{* * *}$ & & \\
\hline
\end{tabular}

${ }^{* * *} p<.001$.

혁신문화와 가치공유를 위한 사회적 역량과의 관계

독립변인인 혁신문화가 매개변인인 원장과의 관계만족도와 동료교사와의 관계만족도가 가치공유를 위한 사회적 역량에 미치는 영향을 살펴본 결과, Table 5 와 같다. 1 단계로 독립변 수가 종속변수에 미치는 영향은 혁신문화가 가치공유를 위한
사회적 역량에 유의미한 영향을 미치는 것으로 나타났고 $(F=$ $89.01, p<.001), B$ 값은 0.35 ( $p<.001$ )고 설명력은 $12 \%$ 였다. 2 단계로 독립변수가 매개변인에 미치는 영향을 확인한 결과 혁 신문화가 관계만족도와 동료교사와의 관계만족도에 유의미 한 영향을 미친다는 앞서 제시된 결과와 동일하다. 3 단계로 독 립변수와 매개변수가 종속변수에 미치는 영향은 독립변인인 
Table 6

The Indirect Effects: Social Competence for Sharing the Value

\begin{tabular}{lcccc}
\hline & & & \multicolumn{2}{c}{$95 \%$ CI } \\
\cline { 4 - 6 } \multicolumn{1}{c}{ Mediators } & Effect & SE & LLCI & ULCI \\
\hline Total & 0.13 & 0.04 & 0.05 & 0.20 \\
Relational satisfaction with principal & 0.00 & 0.04 & -0.07 & 0.07 \\
Relational satisfaction with colleagues & 0.13 & 0.03 & 0.07 & 0.18 \\
\hline
\end{tabular}

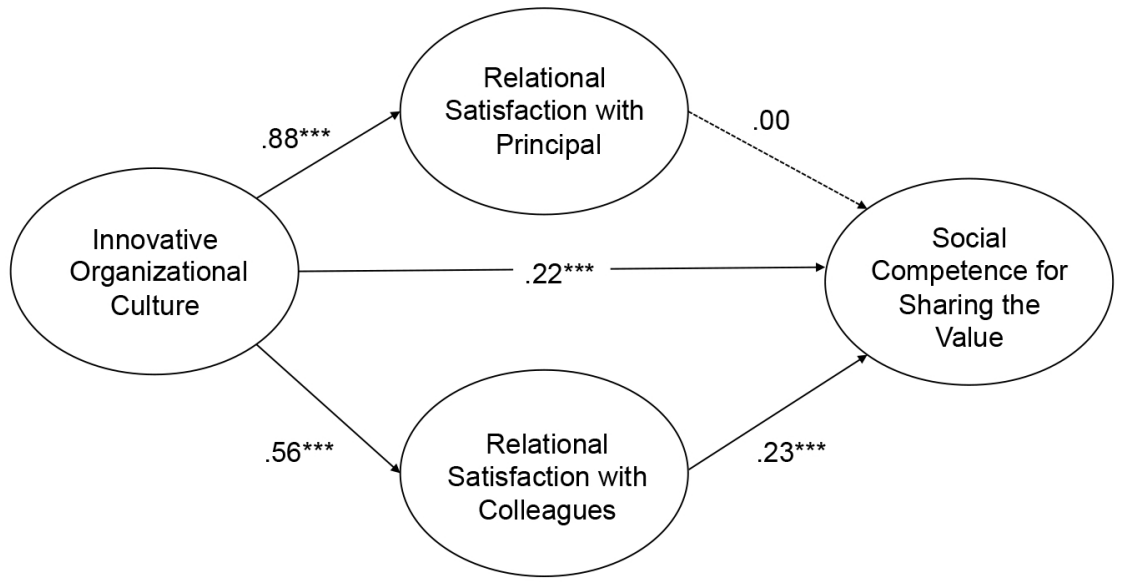

Figure 2. Mediation model: Social competence for sharing the value.

${ }^{* * *} p<.001$.

혁신문화와 매개변인인 원장과의 관계만족도와 동료와의 관 계만족도가 종속변인인 가치 공유를 위한 사회적 역량에 유의 미한 영향을 미치는 것으로 나타났고 $(F=40.93, p<.001)$, 전 체 설명력은 $16 \%$ 였다. 또한, 혁신문화와 가치공유를 위한 사 회적 역량과의 관계에서 $B$ 값은 $0.22(p<.001)$ 로 나타났다. 즉, 매개변인인 원장과의 관계만족도와 동료교사와의 관계만 족도가 투입됨에 따라 설명력은 증가하였고, 혁신문화와 가 치공유를 위한 사회적 역량의 $B$ 값은 앞서 0.35 에서 0.22 로 줄 어들었다. 이는 혁신문화와 가치공유를 위한 사회적 역량과의 관계에서 원장과의 관계만족도와 동료교사와의 관계만족도 는 부분적으로 매개효과를 가짐을 의미한다. 한편, 원장과의 관계만족도는 가치공유를 위한 사회적 역량에 유의미한 영향 을 미치지 않고 $(B=0.00)$ 동료교사와의 관계만족도는 유의미 한 영향을 미치는 것으로 나타났다 $(B=0.23, p<.001)$.이에 매 개효과를 검증하기 위하여 부트스트랩핑으로 표본 수 5,000 개를 재추출하고, $95 \%$ 신뢰구간에서 간접효과 계수의 하한값 (LLCI)과 상한값(ULCI)을 확인하였다(Table 6). 그 결과, 전체 간접효과 크기는 0.13 이였으며, 하한값은 0.05 , 상한값은 0.20 으로 $95 \%$ 신뢰구간 내에 0 이 포함되지 않아 간접효과가 유의
미한 것으로 나타났다. 구체적으로 원장과의 관계만족도의 효 과크기는 0.00 고 하한값이 -0.07 , 상한값이 0.07 로 $95 \%$ 신뢰 구간 내에 0 을 포함하고 있어 간접효과가 유의미하지 않은 반 면, 동료교사와의 관계만족도의 효과크기는 0.13 이고 하한값 이 0.07 , 상한값이 0.18 로 $95 \%$ 신뢰구간 내에 0 이 포함되지 않 아 간접효과가 유의미한 것으로 나타났다. 즉, 혁신문화와 가 치공유를 위한 사회적 역량과의 관계에서 매개변인인 원장과 의 관계만족도와 동료교사와의 관계만족도 중에서 동료교사 와의 관계만족도만 통계적으로 유의미한 매개효과가 있는 것 으로 볼 수 있다. 이에 최종 매개효과 모형은 Figure 2와 같다.

\section{Discussion}

본 연구에서는 유아교육기관의 혁신문화와 교사의 교육공동 체 구현 역량의 관계에서 원장 및 동료교사와의 관계만족도의 매개효과를 살펴보고자 하였다. 연구의 결과를 토대로 논의하 면 다음과 같다.

첫째, 유아교육기관의 혁신문화는 원장 및 동료교사와의 
관계만족도, 교사의 교육공동체 구현 역량의 하위요인들과 정 적 상관을 보이는 것으로 나타났다. 즉, 교사들이 유아교육기 관의 문화를 외부환경의 변화에 적극적으로 반응하고 내부에 서 발생하는 문제에도 유연하게 자발적으로 협력하는 진취적 인 문화로 인식할수록 원장 및 동료교사와의 관계만족도와 유 아교육공동체 구현 역량이 높았다. 그 중 유아교육기관의 혁 신문화와 원장 및 동료교사와의 관계만족도간의 상관은 보 육시설의 조직문화 중 변화를 기본가정으로 하는 개발문화 와 동료교사 및 시설장과의 관계만족도간의 관계를 밝힌 M.H. Kim (2011)의 연구뿐 아니라 유치원 교사가 인식하는 혁신 문화와 동료애간의 정적 상관을 보여준 Jo (2015)의 연구결과 와 그 맥을 같이한다. 조직문화가 구성원들이 서로 간에 관계 를 맺는 방식에서 드러나는 신념과 기대로 정의되며(Fullan \& Hargreaves, 1996), 그 유형 중에 하나인 혁신문화의 키워드가 상호간의 의사교환 및 협력을 통한 유연한 문제해결과정이라 는 점을 생각해본다면 혁신문화와 원장 및 동료교사와의 관계 만족도 간의 상관은 어느 정도 예측가능한 부분이다. 또한 두 변인 간의 상관은 여성으로 구성된 소규모 집단인 유아교육기 관은 매우 사적이며 인간관계 중심의 의사소통 방식을 활용한 다(E.-H. Park, 2009)는 점에서 유아교육기관의 독특한 조직구 조와 문화적 특성이 상호작용한 결과로 사료된다.

더불어 유아교육기관에서 교사가 인식하는 혁신문화와 유 아교육공동체 구현 역량 간에도 정적 상관이 있으며, 이러한 상관을 토대로 혁신문화는 교사의 유아교육공동체 구현 역 량에 정적 영향을 미치는 요인이 되는 것으로 나타났다. 직접 적인 관련 연구는 없으나, 이와 같은 결과는 조직문화가 유아 교사의 조직만족과 조직몰입에 영향을 미친다는 선행연구들 (Jang, 2014; M.-J. Kim \& Park, 2014; J.-M. Lee \& Kim, 2013)의 결과로부터 그 타당성을 유추할 수 있다. 조직문화는 조직의 구성원들 모두가 당연한 것으로 인정하는 보편적인 가치체계 로서(Moon \& Chun, 2001) 구성원들의 태도 및 행동에 영향을 미친다. 그 중 혁신문화는 구성원 상호간의 협력을 통해 동기 를 유발하고 조직의 변화와 혁신에 초점을 맞추어 조직의 최 대 지원을 받으며 개인이 자율적으로 일을 수행할 수 있기에 조직과의 일체감을 향상시킬 수 있다(E. Y. Choi, 2007). 따라 서 혁신문화의 특성이 강한 유아교육기관의 교사들은 상호 협 력적 관계를 통한 혁신을 지향하는 기관의 가치를 공유하고 있을 가능성이 높고 이는 나아가 교사의 행동에도 영향을 미 치게 되는 바, 구성원들과 함께 무언가를 고민하고 구성해나 가는 과정에 대한 인식 및 공동체 구성원으로서의 역할수행 역량이 높을 것으로 보인다. 혁신문화에서 구성원들은 일정
부분의 위험을 감수하면서 자신과 조직의 성장을 위해 자발적 이고 적극적인 노력을 수행한다는 I.-K. Han (2012)의 논의 또 한 이를 뒷받침한다. 이상의 결과들은 유아교육기관에서 교육 공동체의 구현을 추구하고자 할 때, 구성원들 간의 관계성 및 교사의 유아교육공동체 구현 역량의 증진을 위한 다양한 노력 이 필요하며 그러한 노력의 효율성을 높이는 방안의 하나로 기관의 조직문화를 혁신적이고 친화적으로 문화로 바꾸어 나 가는 것이 의미 있음을 시사한다.

한편, 원장 및 동료교사와의 관계만족도가 높을수록 유아 교육공동체를 구현하는데 필요한 교사의 역량이 높다는 결과 가 확인되었다. 이러한 결과를 뒷받침할 직접적인 연구가 없 어 논의에 제한이 있다. 그러나 교육공동체는 바람직한 교육 이상을 설정하고 이를 실현하기 위해 모든 구성원들이 주체로 참여하여 공동으로 노력하는 공동체로서(Suh, 2005), 이러한 공동체를 구현함에 있어서 '함께'라는 의식의 공유는 매우 중 요한 요소이다(H.-S. Shin, 2004). 다시 말해, 교육공동체는 인 간과 인간의 상호 '관계'에 그 중심을 두고 있다고 할 수 있으 며, 이에 유아교육공동체 구현을 위한 교사의 역량이 공동체 의 주체인 원장, 동료교사와의 관계에 대한 만족감과 관련성 이 있다는 것은 자연스러운 결과로 생각된다. 이와 더불어, 기 관 구성원들과의 관계가 교사의 직무 만족을 결정하는 요인 중 하나(Jorde-Bloom, 1989)라는 맥락에서 살펴볼 때, 교사가 자신의 직무에 대한 높은 만족감을 가지면 자신의 직무에 애 착을 가지고 헌신하게 되며 학교조직에 소속감을 가지고 계속 근무하고 싶은 의욕을 보인다는 연구결과들(Y. K. Lee, 1998; Mathieu \& Zajac, 1990; E. H. Seo \& Lee, 2002)에 의해서도 두 변인간의 관련성은 어느 정도 설명될 수 있다. 이러한 결과는 유아교육기관이 교육공동체로서의 건강성을 위협받고 있는 현 시점의 어려움을 교사를 중심으로 하는 구성원 간의 긍정 적인 관계를 통해 극복할 수 있음을 시사한다.

둘째, 유아교육기관의 혁신문화와 교사의 교육공동체 구현 역량의 관계에서 동료교사와의 관계만족도가 부분매개를 하 는 것으로 나타났다. 이는 유아교육기관의 혁신문화가 교사 의 유아교육공동체 구현을 위한 역량에 직접적으로 영향을 미 치기도 하지만, 동료교사와의 관계만족도에 영향을 미쳐서 이 를 통해 유아교육공동체 구현 역량에 영향을 주는 간접적 효 과도 있음을 보여주는 것이다. 즉, 동료교사와의 관계만족도 는 혁신문화가 교사의 유아교육공동체 구현 역량에 미치는 영 향을 촉진 내지 강화하는 역할을 한다는 것이다. 이러한 결과 는 공교육의 정상화와 학교혁신을 목적으로 각 시도 교육청, 각 급 학교 별로 진행 중인 교육혁신 정책들이 단순히 교육과 
정의 혁신, 기관문화의 혁신을 위한 계획 및 관리에 초점을 두 기보다는 근본적으로 학교를 구성하는 구성원들 간, 특히 동 료교사들 간의 긍정적인 관계를 형성하기 위한 노력이 함께 이루어질 때 더욱 그 빛을 발할 수 있음을 시사한다. 나아가 본 연구 결과와 함께 유아교육기관이 관계지향문화일 때 교사가 행복한 것으로 밝혀진(H.-E. Lee, 2017) 사실은 유아교육기관 이 혁신문화 속에서 관계 지향적 조직문화를 유도하는 노력이 교사의 행복을 추구하는 학교혁신이나 교육공동체의 구현에 중요하다는 것을 시사한다. 유아교육기관은 비교적 규모가 작 고 조직원의 수가 적어 조직 내 인간관계가 매우 밀접한 특징 을 가지며(J.-H. Kim \& Moon, 2007; Min, 2010), 교사들 사이의 관계가 수평적이고 원활한 소통이 이루어질 때 구성원들 간의 오해에서 비롯된 스트레스가 적고 이에 따른 직무만족도가 높 아지는 특징이 있다(M. S. Lee, 2000). 구성원 간의 긍정적인 관 계 형성을 통한 유아교육공동체의 구현은 교사의 역량 강화나 학교혁신을 넘어 유아교육의 목적인 유아의 건강한 발달에 필 수적인 요인이다. 이러한 측면에서도 구성원 간의 관계 증진을 위한 기관 및 구성원들의 다양한 노력이 요구되는 바이다.

한편, 본 연구결과에서 원장과의 관계만족도는 혁신문화 와 교사의 교육공동체 구현 역량의 관계에서 유의미한 영향을 미치지 않는 것으로 나타났다. 이러한 결과는 원장이라는 위 치 및 역할 특성에서 비롯되었을 것이라 사료된다. 유아교육 기관에서 교사는 원장이 아닌 동료교사와 교육활동과 유치원 운영에 관한 일의 대부분을 함께 진행하며 협동하는 등, 동료 교사와 직접적으로 관계하는 시간이 원장과 관계하는 시간보 다 상대적으로 많은 편이다. 따라서 실제로 혁신문화를 이끌 어가고 형성하는 주체 또한 교사이다. Kelly (1992/1998)에 따 르면 조직의 성공에 리더가 미치는 영향력은 $20 \%$ 에 불과하며 $80 \%$ 는 하위 구성원에 의한 것이라고 제시한 것과 같이 리더 인 원장과의 관계가 낮은 혁신문화에 속한 교사의 교육공동체 구현 역량을 증진시키기엔 그 영향력이 크지 않은 것으로 판 단된다. 이는 원장의 긍정적인 지지가 교사와 원장과의 관계 에 도움을 줄 수 있겠지만 원장과 교사의 관계는 교사간의 관 계보다는 상대적으로 상하관계에 있어 유아교육기관에서 원 장은 교사들과 함께 실제 문제를 끊임없이 고민하고 부딪혀가 는 동반자적 존재이기보다는 교사들에게 업무를 할당하고 의 사결정을 하는 위치(S.-Y. Choi \& Lee, 2011)에 있기 때문으로 볼 수 있다. 실제 본 연구에서 사용한 설문의 내용도 전체적으 로 인사관리 및 평가와 관련된 원장의 역할을 중심으로 한 관 계 만족도를 묻고 있다. 이러한 연구 결과는 혁신문화를 실천 하는 기관에서 원장이 교육공동체 구현에 보다 많이 기여하기
위해서는 관리와 평가 위주의 원장 역할을 넘어 교사들과의 관계형성에 보다 노력하여야 함을 시사한다. 또한, S. Lee, Kim 과 Yoo (2017)에 따르면 경력에 따라 경력이 높은 교사는 원장 선생님의 지시나 지도보다는 교사의 자기 주도적 역할 수행에 따른 만족이 중요하다고 인식하지만 경력고사와 초임교사 모 두 서로 이해하고 공감하며 협력하는 것이 중요하다고 인식하 였다. 이러한 결과는 혁신문화 속에서 관계 지향적 조직문화 형성을 동시에 추구해야 할 필요성을 다시금 인식시켜 준다. Douglass (2017)에 따르면 조직문화는 구성원의 행동과 직무 관련 경험뿐 아니라 각 구성원이 수행 실제를 개선하고자 하 는 노력에도 큰 영향을 미친다. 그러므로 원장은 기관의 혁신 문화 조성을 위한 노력에 그치지 않고 긍정적인 관계적 문화 도 함께 형성할 수 있도록 교사 간 및 원장-교사 서로 이해하 고 공감하여 협력하는 관계를 형성하기 위한 개별 또는 집단 프로그램을 적극 수행하여 유아교육기관이 건강한 교육공동 체로 나아갈 수 있는 토대를 만들어야 할 것이다.

본 연구는 유아교육기관의 혁신문화와 교육공동체 구현 을 위한 교사의 역량 간의 관계에서 원장 및 동료교사와의 관 계만족도의 매개효과를 알아봄으로써, 유아교육공동체 형성 을 위한 교사의 역량 강화 방안으로 혁신문화 형성 및 구성원 간의 관계 증진의 중요성을 확인하였다. 그러나 본 연구는 기 관 구성원들과의 관계만족도를 측정하기 위해 원장 및 동료 교사와의 관계에 관한 관계만족도 도구의 일부만 사용하였으 며, 특히 동료교사의 관계만족도는 3 개 문항으로 측정되었다 는 점에서 제한점이 따른다. 그리고 유아교육기관 내에는 원 감, 조리사 등 다양한 구성원들이 존재하며 이들과의 관계 역 시 기관의 운영 및 관리와 관련된 역동에 영향을 미칠 수 있다. 또한, 유아교육기관 외부에 존재하는 부모, 지역사회 등과 같 은 구성원들과의 관계도 기관 내 역동에 영향을 주는 주요 변 인이라는 점을 고려했을 때, 추후 이러한 점을 보완하여 교사 의 유아교육공동체 구현 역량을 증진시키기 위한 보다 다양한 방안을 모색할 필요가 있다. 한편, 유아교육기관의 조직문화 는 혁신문화 뿐 아니라 집단문화, 위계문화 그리고 합리문화 가 공존한다고(I.-S. Cho, 2005; Y. M. Kim \& Lee, 2018) 보고된 바, 이를 고려한 추후 연구가 실시될 필요가 있다. 이와 함께 실제 혁신문화를 형성하고 있는 유아교육기관의 원장 및 교사 들과의 인터뷰를 통해 혁신문화 형성 과정을 살펴 교육공동체 로 나아가는 과정에서 원장 및 교사들과의 관계 형성이 실제 로 어떠한 의미를 갖는지를 이해하는 것도 유아교육공동체 구 현의 방법론 모색에 도움이 될 것이라 사료된다. 


\section{Acknowledgements}

This work was supported by the Ministry of Education of the Republic of Korea and the National Research Foundation of Korea (NRF-2017S1A3A2067778).

\section{Conflict of Interest}

No potential conflict of interest relevant to this article was reported.

\section{References}

\section{In English}

Baron, R. M., \& Kenny, D. A. (1986). The moderator-mediator variable distinction in social psychological research: Conceptual, strategic, and statistical considerations. Journal of Personality and Social Psychology, 51(6), 1173.

Cameron, K. S., \& Quinn, R. E. (2011). Diagnosing and changing organizational culture: Based on the competing values framework. San Francisco, CA: John Wiley \& Sons.

Douglass, A. L. (2017). Leading for change in early care and education: Cultivating leadership from within. New York: Teachers College press.

Fullan, M., \& Hargreaves, A. (1996). What's worth fighting for in your school? Revised Edition. New York: Teachers College Press.

Hawes, D. J. (1989). Communication between teachers and children: A counselor consultant trainer model. Elementary School Guidance \& Counseling, 24(1), 58-67.

Hayes, A. F. (2019). Process for SPSS and SAS (Version 3.3) [Macro]. Retrieved from https://www.processmacro.org/download. html

Jorde-Bloom, P. (1989). Professional orientation: Individual and organizational perspectives. Child and Youth Care Quarterly, 18(4), 227-242. doi:10.1007/BF01083871

Kimberly, J. R., \& Quinn, R. E. (1984). New futures: The challenge of managing corporate transitions. Burr Ridge, IL: Dow Jones-Irwin.

Malaty, G. (2006). What are the reasons behind the success of Finland in PISA? Matilde, 29, 4-8.

Mathieu, J. E., \& Zajac, D. M. (1990). A review and metaanalysis of the antecedents, correlates, and consequences of organizational commitment. Psychological Bulletin, 108(2),
171-194. doi:10.1037//0033-2909.108.2.171

Parker, R., \& Bradley, L. (2000). Organizational culture in the public sector: Evidence from six organizations. International Journal of Public Sector Management, 13(2), 125-141. doi:10.1108/09513550010338773

Schein, E. H. (1996). Culture: The missing concept in organization studies. Administrative Science Quarterly, 41(2), 229-240. doi: $10.2307 / 2393715$

\section{In Korean}

Cho, I.-S. (2005). A study on the relationship between the quality of child care service and the organization culture of child care center (Doctoral dissertation). Retrieved from http://www. riss.kr/link?id=T9810965

Cho, S.-Y. (2004). Teacher's work satisfaction and work stress in child care center. Korean Journal of Child Care and Education, 36, 23-44.

Choi, E. Y. (2007). A study on the effects of organizational culture on performance measurement system-Focused on the perception of organizational members on performance measurement system-(Master's thesis). Retrieved from http://www.riss.kr/ link?id=T11359119

Choi, S.-Y., \& Lee, D.-K. (2011). The difficulties of privatekindergarten teachers - Concentrating on human relations. Early Childhood Education Research \& Review, 15(5), 77 102.

Chung, K., Park, H., Gu, S., Kim, H., Park, H., \& Son, H. (2018). Suggestions for realization of ddadeutan educational community based on the concepts of Cheong (情) and Wooriuisik (weness). Journal of Learner-Centered Curriculum and Instruction, 18(14), 849-873. doi:10.22251/ jlcci.2018.18.849

Chung, K., Yoon, G.-J., Kyun, J.-Y., Cha, J.-R., \& Park, H. (2016). The figure and practical tasks of 'warm' early childhood educational community for recovering healthiness of early childhood education. Journal of Early Childhood Education, 36(1), 153-182. doi:10.18023/kjece.2016.36.1.007

Chung, K., Yoon, G.-J., \& Moon, J. (2017). Mediating effects of psychological empowerment on the relationship between organizational culture and relationship satisfaction with members of kindergarten teachers. Journal of LearnerCentered Curriculum and Instruction, 17(3), 237-264. doi:10.22251/jlcci.2017.17.3.237

Chung, K., Yoon, G.-J., \& Park, H. (2016). Exploring the components of community members' core competence for establishing a 'warm' early childhood educational community. Teacher Education Research, 55(2), 253-270. doi:10.15812/ ter.55.2.201606.253 
Chung, K., Yoon, G.-J., \& Park, H. (2017). Development of the teacher's competence scale for building early childhood educational community. Journal of Learner-Centered Curriculum and Instruction, 17(9), 1-28. doi:10.22251/jlcci.2017.17.9.1

Fredrickson, B. (2015). Positivity: Top-notch research reveals the 3 to 1 ratio that will change your life (M. Woo \& S. Choi, Trans.). Anyang: Mulpure. (Original work published 2009).

Han, I.-K. (2012). The effects of organizational culture type and strength on job satisfaction and organizational commitmentFocused on the central govermente officers-(Doctoral dissertation). Retrieved from http://www.riss.kr/link?id= T12748147

Han, S. H. (2000). Hakgyoui saengmyeongseong buhwalgwa hakseupsaengtaegye [학교의 생명성 부활과 학습생태계]. Korean Educational Review, 6(1), 56-82.

Hur, H.-D. (2005). A study on the content analysis for the roles of school community members. The Journal of Educational Administration, 23(2), 281-302.

Jang, Y. Y. (2014). The effects of the Montessori early childhood education teachers self-leadership and organizational cultures for organizational concentration (Master's thesis). Retrieved from http://www.riss.kr/link?id=T13373586

Jo, D.-H. (2015). An analysis of variables related with kindergarten organization on the job satisfaction of kindergarten teachers (Doctoral dissertation). Retrieved from http://www.riss.kr/ link?id=T13708811

Kang, M. S. (2015). A qualitative study on the task experience of child care teachers-Focus on organizational culture-. Journal of Educational Innovations Research, 25(3), 67-88.

Kelly, R. E. (1998). The power of followership (D. H. Chang, Trans.). Seoul: Koreaonebooks. (Original work published 1992)

Kim, C.-G. (2000). A study on the relationship between the organizational culture and teacher's organizational commitment of school. Journal of Education \& Culture, 6, 139-172.

Kim, E. Y. (2011). An analysis of the impacts of learning organization level on organizational commitment in public organization with reference to motivation and job satisfaction as mediated variables (Doctoral dissertation). Retrieved from http:// www.riss.kr/link?id=T12319902

Kim, J.-H., \& Moon, H.-J. (2007). Influence of director's leadership on teachers' empowerment and organizational effectiveness in early childhood educational institutes. Korean Journal of Child Studies, 28(6), 73-84.

Kim, M.-H. (2011). A study on edu-care facilities' organizational culture and teachers' job satisfaction (Master's thesis). Retrieved from http://www.riss.kr/link?id=T12332568

Kim, M.-J., \& Park, S.-H. (2014). The effects of emotional intelligence and collaborative culture on early childhood teacher's empowerment. Korea Journal of Child Care and Education, 87, 187-210.

Kim, Y. M., \& Lee, K. N. (2018). The effects of a principal's coaching-type leadership, early childhood teachers organizational commitment, and teacher efficacy on job satisfaction. The Journal of Eco-Early Childhood Education, 17(2), 53-77. doi:10.30761/ecoece.2018.17.2.53

Koh, K. M., \& Lee, S. K. (2017). The effects of childcare teacher's job satisfaction on teacher-child interaction and familyteacher communication. Journal of Learner-Centered Curriculum and Instruction, 17(13), 397-414. doi:10.22251/ jlcci.2017.17.13.397

Lee, A.-K., Yeo, J.-Y., Jung, S., \& Byun, S. S. (2013). Relations on communication competence, job-stress and job-satisfaction of clinical nurse. The Journal of Korea Contents Association, 13(12), 299-308. doi:10.5392/JKCA.2013.13.12.299

Lee, G. S., \& Hwang, B. J. (2017). Effects of individual creativity and organizational members' value innovative culture perception on innovative performances and management outcomes-The roles of mediating innovative behaviors and knowledge-sharing-. Journal of Service Research and Studies, 7(3), 71-91. doi:10.18807/jsrs.2017.7.3.071

Lee, H.-E. (2017). A structural analysis of early childhood teachers' job performance and its related variables: Focusing on job satisfaction, happiness, relationship-oriented organizational culture. Journal of Future Early Childhood Education, 24(1), 231-256. doi:10.22155/JFECE.24.1.231.256

Lee, J.-M., \& Kim, H.-S. (2013). A study on the influence of organizational culture to organizational commitmentFocused on mediated effect of child-care teachers's innovator cognition style-. Korea Journal of Child Care and Education, 80, 65-83.

Lee, J. Y. (2012). Team-jojik munhwa jeokapdoga team manjokgwa jojik manjoge michineun yeonghyang: Gaein sujungwa team sujunui yeongu [팀-조직 문화 적합도가 팀 만족과 조 직 만족에 미치는 영향: 개인 수준과 팀 수준의 연구] (Doctoral dissertation). Retrieved from http://www.riss.kr/ link?id=T12947390

Lee, M. S. (2000). The narrative story about how to become a childhood teacher (Doctoral dissertation). Retrieved from http://www.riss.kr/link?id=T11333939

Lee, S., Kim, E., \& Yoo, J. (2017). Director-teacher partnership for nursery teacher's subjective attitude analysis. Journal of Korean Society for Scientific Study of Subjectivity, 35, 59-83.

Lee, Y.-J., \& Kang, T.-W. (2014). Effect of communication with a guardian of a recipient of a long-term care program on job satisfaction of care helpers. The Journal of Korea Contents Association, 14(5), 156-165. doi:10.5392/JKCA.2014.14.05.156

Lee, Y. K. (1998). The relationship among the job satisfaction, the physical work environments and the organizational 
commitment in kindergarten teachers. Korean Journal of Early Childhood Education, 18(1), 223-241.

Min, H.-Y. (2010). A study on the relationship between childcare teachers ' perceptions of the directors' leadership behavior type, decision making and teacher efficacy. Journal of Young Child Studies, 13, 101-115.

Moon, D.-S., \& Chun, G.-Y. (2001). The relationship between organizational socialization, cultural characteristics, and organizational effectiveness of the sport organization. The Korean Journal of Physical Education, 40(3), 451-463.

Oh, H.-J., \& Kang, K.-S. (2006). The impact of the culture of teacher community in school organization on school evaluation. Inha Education Forum, 12, 1-32.

Ohem, M.-S., \& Jeong, E.-H. (2011). A mediating effect of psychological empowerment on the relationship between organizational culture perceived by social workers and organizational innovation activities. Journal of Community Welfare, 37, 229-258.

Park, E.-H. (2009). The influence of rearing attitude of parents and social support on adjustment in school of children from multicultural families-Focused on the mediateor effects of selfesteem-(Master's thesis). Retrieved from http://www.riss.kr/ link?id=T11971625

Park, G. W., \& Kwon, Y. H. (2015). Jingmu manjogui yeonghyangyoin: jojingmunhwawa eommuteukseongeul jungsimeuro [직무 만족의 영향요인: 조직문화와 업무특 성을 중심으로]. Proceedings of 2015 Conference of the Korean Association for Local Government Studies (pp. 431-444), Busan, South Korea: The Korean Association for Local Government Studies.

Park, K. M. (2018, October 15). 'Adonghakdae uisim' sinsang teollin eorinijip gyosa sumjinchae balgyeon ['아동학대 의 심' 신상 털린 어린이집 교사 숨진채 발견]. Hankyoreh. Retrieved January 28, 2019, from http://www.hani.co.kr/ arti/society/area/865897.html\#csidx0a8fc51dbd58b4ab656 $677 \mathrm{~d} 86986515$
Park, M. (2012). The relationship between teachers' perceived organizational culture of the early-childhood educational institution and their empowerment (Master's thesis). Retrieved from http://www.riss.kr/link?id=T12934527

Seo, E. H., \& Lee, M. S. (2002). A study on the job satisfaction, organizational commitment and turnover intention of kindergarten teachers. The Journal of Korea Open Association for Early Childhood Education, 7(3), 155-170.

Seo, Y. R. (2006). The effects of elementary principal's leadership life skill on school organizational culture and organizational effectiveness (Doctoral dissertation). Retrieved from http:// www.riss.kr/link?id=T10873337

Shin, D.-H. (2004). Child care teacher's job stress and job satisfaction (Master's thesis). Retrieved from http://www.riss.kr/ link?id=T10040840

Shin, H.-S. (2004). The formation and development of educational community: Implications from oriental and western community thoughts. The Journal of Educational Administration, 22(1), 135-156.

Suh, G. W. (2005). Educational anthropological reinterpretation of an educational community: A case study of Sahndle elementary school. Anthropology of Education, 8(2), 127-179.

\section{ORCID}

Kai-sook Chung

Hee-kyung Park Jiyeon Kim
http://orcid.org/0000-0003-4472-824X http://orcid.org/0000-0002-7284-6465 https://orcid.org/0000-0002-5895-5761
Received February 21, 2019

Revision received March 27, 2019

Accepted April 12, 2019 